\title{
Verification of electric steel punching simulation results using microhardness
}

\author{
Sampsa Vili Antero Laakso ${ }^{1}$ (D) Ugur Aydin $^{2}$ (D) $\cdot$ Peter Krajnik $^{1}$ (D)
}

Received: 28 May 2020 / Accepted: 15 December 2020 / Published online: 6 January 2021

(C) The Author(s) 2021

\begin{abstract}
One of the most dominant manufacturing methods in the production of electromechanical devices from sheet metal is punching. In punching, the material undergoes plastic deformation and finally fracture. Punching of an electrical steel sheet causes plastic deformation on the edges of the part, which affects the magnetic properties of the material, i.e., increases iron losses in the material, which in turn has a negative effect on the performance of the electromagnetic devices in the final product. Therefore, punchinginduced iron losses decrease the energy efficiency of the device. FEM simulations of punching have shown significantly increased plastic deformation on the workpiece edges with increasing tool wear. In order to identify the critical tool wear, after which the iron losses have increased beyond acceptable limits, the simulation results must be verified with experimental methods. The acceptable limits are pushed further in the standards by the International Electrotechnical Commission (IEC). The new standard (IEC TS 6003430-2:2016) has much stricter limits regarding the energy efficiency of electromechanical machines, with an IE5 class efficiency that exceeds the previous IE4 class (IEC 60034-30-1:2014) requirements by 30\%. The simulations are done using Scientific Forming Technologies Corporation Deform, a finite element software for material processing simulations. The electrical steel used is M40050A, and the tool material is Vanadis 23, a powder-based high-speed steel. Vanadis 23 is a high alloyed powder metallurgical highspeed steel with a high abrasive wear resistance and a high compressive strength. It is suitable for cold work processing like punching. In the existing literature, FEM simulations and experimental methods have been incorporated for investigating the edge deformation properties of sheared surfaces, but there is a research gap in verifying the simulation results with the experimental methods. In this paper, FEM simulation of the punching process is verified using an electrical steel sheet from real production environment and measuring the deformation of the edges using microhardness measurements. The simulations show high plastic deformation $50 \mu \mathrm{m}$ into the workpiece edge, a result that is shown to be in good agreement with the experimental results.
\end{abstract}

Keywords Microhardness $\cdot$ Electric steel sheet punching $\cdot$ FEM simulation $\cdot$ Experimental verification

\section{Introduction}

Electromechanical machines like electric motors and generators have great potential in energy savings through improved energy efficiency. The International Electrotechnical Commission has released the new standard (IEC TS 60034-30-2:2016) where the IE5 energy efficiency class requires efficiency of over $75 \%$ in low powered machines $(<1 \mathrm{~kW})$ and over $95 \%$

Sampsa Vili Antero Laakso

sampsal@chalmers.se

1 Department of Industrial and Materials Science, Chalmers University of Technology, Gothenburg, Sweden

2 ABB Oy, Marine and Ports, Helsinki FI-00980, Finland efficiency in high powered machines (>10 kW). In order to meet these requirements, new low loss materials for electrical motors have been developed and many new technological advancements have been implemented in the design of electric motors. However, one of the major contributors to electric losses in motors, manufacturing, has been neglected in the development. It has been estimated that $5 \%$ of the total electric losses of a motor is due to manufacturing and the added iron losses caused by it [1-3]. This paper investigates how well a simulation model can predict the plastic deformation on the part surface caused by the manufacturing process.

\subsection{Electric losses in motors}

Losses of electric motors include mechanical (friction) losses, windage losses, iron losses (magnetic core losses), and 
Fig. 1 Relative losses at different applied stresses as in Naumoski et al. [10]
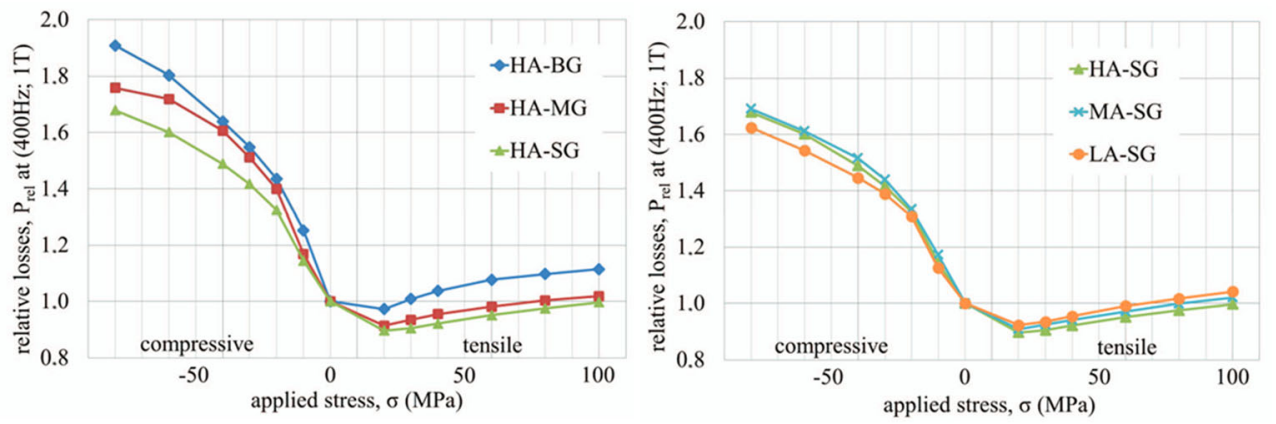

resistance losses in the stator and in the rotor. Iron losses are caused by eddy currents and hysteresis in the stator. Iron losses and resistance losses are increased with increased material deformation [4-8]. This paper will focus on determining the iron losses in stator sheet manufacturing.

\subsection{Motor designs for improved energy efficiency}

There are some technological advancements in electric motor designs that improve the energy efficiency. Variable speed drives, VSD's, have higher efficiency than induction drives at lower speeds and do not need to be over-dimensioned. Using optimal flux in lower speed applications reduces iron losses and winding losses. Iron losses are proportional to magnetic flux density and frequency. Decreasing frequency decreases iron losses. Winding losses are proportional to voltage and thus inversely proportional to the square of magnetic flux. In order to maintain constant torque at low speeds, the magnetic flux can be increased by increasing voltage instead of frequency and thus decreasing also winding losses.

Winding losses can be reduced by increasing the following individually or in combination: the winding wire diameter, packing density, and number of turns. All the solutions require optimization. Increasing only the wire diameter requires larger stator slots and thus the magnetic flux losses in stator increase. Increasing the wire diameter at the cost of the number of turns increases the iron losses with increasing magnetic flux, but the slot size does not need modification. Increasing wire diameter and stator length decreases winding losses at the cost of material usage and larger motor. Increasing only the stator length increases the winding losses, but it is compensated with reduced iron losses. The longer stator reduces heating of the motor and the smaller cooling fans reduce mechanical losses. Joule losses in rotor bars can be decreased by improving the conductivity of the rotor bar material and improving the manufacturing process to minimize manufacturing defects. Mechanical losses can be minimized with good balancing, minimizing friction, and optimizing the cooling fans and fins. Iron losses can be minimized by using better steel lamination materials with lower losses. Stress relieving heat treatment can reduce the iron losses in the laminations. Other efficiency increasing technologies are different lamination geometries, different winding geometries, different placement of the magnets, and using permanent magnets [9].

Regardless of the motor design, decreasing the iron losses of the lamination steel sheets will improve the efficiency of the motor. Additionally, iron losses are among the major individual contributors to the losses on average with $30 \%$ of the total losses.

\subsection{Effect of elastic and plastic deformation on iron losses}

Iron losses are dependent on material stress state and deformations. Naumoski et al. [10] investigated six different electrical steels under applied load in elastic regimen $\sigma \epsilon[-80$;+ $100 \mathrm{MPa}$ ] using single strip testing setup to measure iron losses. The steels are designated $\mathrm{H} / \mathrm{M} / \mathrm{L}+\mathrm{A}$ based on high,
Fig. 2 Energy loss densities at different stresses, undeformed sample (left) and sample with $1 \%$ plastic deformation (right), as in Aydin et al. [11]

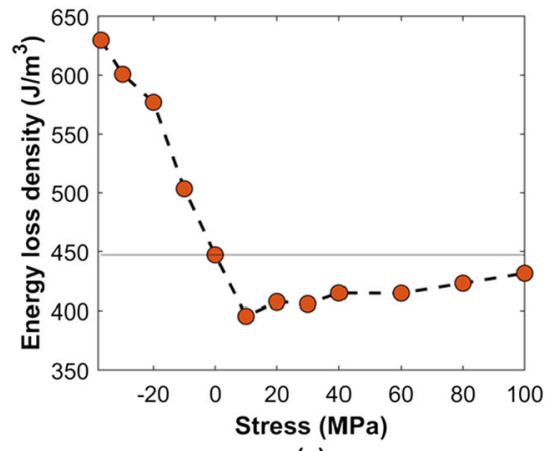

(a)

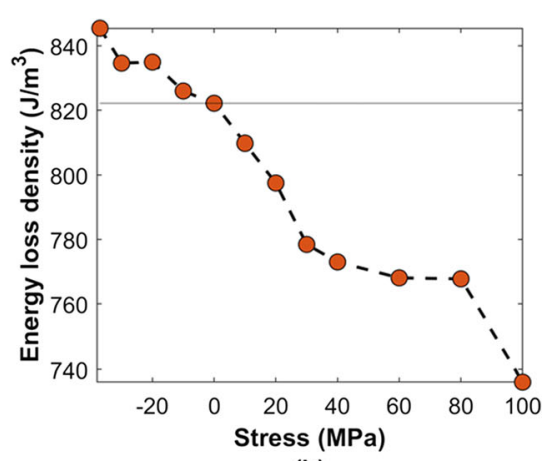

(b) 
Fig. 3 Different stator stacking layouts: uniform cross section, $60^{\circ}$ overlapping "staircase" segments, and $10^{\circ}$ coincident segments [16]
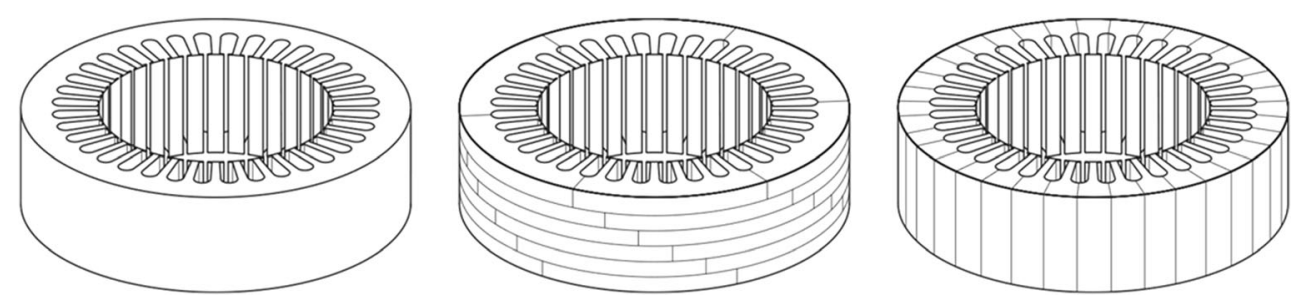

medium, or low alloying content. The second part of the designation is based on the grain side: $\mathrm{B} / \mathrm{M} / \mathrm{S}+\mathrm{G}$ for big, medium, or small grain size. The results in Fig. 1 show that stresses have a major effect on iron losses. Small under 20-MPa tensile stresses decrease the hysteresis losses, but after $20 \mathrm{MPa}$, the losses begin to increase. Compressive stresses increased the losses [10].

Aydin et al. [11] have done similar experiments with plasticly deformed specimen loaded with elastic stresses. The undeformed specimen and specimen with $1 \%$ plastic strain are measured for energy loss density under applied elastic stress $\sigma \epsilon[-30 ;+100 \mathrm{MPa}]$ shown in Fig. 2. The deformed specimen shows $73 \%$ average increase of energy loss density compared to the undeformed sample [11]. This was obtained at $1 \%$ of plastic deformation while in punching, the deformation is $200 \%$ or more. It has not yet been investigated how much exactly the electric losses change with higher plastic strains, but they are expected to increase significantly.

\subsection{Stator and rotor manufacturing}

Stator and rotor plates are cut from a larger roll of electric steel sheet using punching. Punching is a manufacturing process where a punching tool with desired part geometry is pushed through the workpiece. The workpiece is supported with a die, with reverse geometry of the punch. The workpiece is left with a punch shaped hole. In punching, the material undergoes plastic deformation and finally fracture. Li et al. have shown the strain hardening effect to be a major cause for increased hardness and deformation on the cut edge of punched sheets

Table 1 Properties and alloying elements of the M400-50A electrical steel

\begin{tabular}{lll}
\hline Property & Value & Units \\
\hline Young's modulus & $200-210$ & $\mathrm{GPa}$ \\
Yield stress $\left(R_{\mathrm{p} 02}\right)$ & $>280$ & $\mathrm{MPa}$ \\
Ultimate tensile strength $\left(R_{\mathrm{m}}\right)$ & $>400$ & $\mathrm{MPa}$ \\
Hardness (Vickers HV5) & 165 & $\mathrm{HV} 5$ \\
Thermal conductivity at $100{ }^{\circ} \mathrm{C}$ & 25 & $\mathrm{~W} / \mathrm{mK}$ \\
Density & 7700 & $\mathrm{Kg} / \mathrm{m}^{3}$ \\
Carbon content & $\leq 0.005$ & $\mathrm{wt} \%$ \\
Si + Al content & $<2.8$ & wt. $\%$ \\
\hline
\end{tabular}

[12]. The plastic deformation on the edges of a part affects the magnetic properties of the material, i.e., increases iron losses in the material; therefore, alternative methods have been investigated like laser cutting, water jet cutting, and wire EDM $[13,14]$. Laser cutting does not leave burr or deformations on the cut but causes high thermal effects on the cut surface, which have an even higher negative effect on the losses than plastic deformation [15]. Some manufacturers use laser cutting and anneal the products afterwards to mitigate the thermal effects. Water jet cutting and wire EDM processes are not capable of competitive production speed, but especially EDM leaves the cut surface nearly deformation free. Punching can be done either with large tools and one whole stator/rotor section is cut in one cycle or the section can be cut in segments using multiple cycles, which is the case especially with larger stator/rotor diameters. Figure 3 shows different stator stacking layouts and segment sizes. The layout affects the air gap between the segments that affect the flux density and magnetomotive force. The smaller the air gap, the better output; thus, the uniform cross section is ideal [16].

\subsection{Simulation of the punching process}

FEM simulations of punching allow to estimate cut surface quality, tool wear and forces, and the effect of the process parameters, but the quantitative accuracy of the simulations is strongly dependent on the modeling accuracy of the geometry and tool properties, such as the misalignment of the tool or tool deflections [17]. Simulation error can be evaluated by measuring the punching force in real process and comparing that to the simulated punching force [18]. Ghadbeigi et al. [19] used Digital Image Correlation (DIC), optical microscopy, nanohardness measurements, and dislocation density mapping to investigate the punching-induced deformation on the cut edge of electrical steels in punching. Their results show interesting behavior with increased punching speed, where higher punching speed reduces the deformation. This is invaluable information for manufacturing of electrical steel products, since the speed increases productivity but also decreases the deformation-induced losses. The results should be applied carefully however, since the higher cutting speed increases the tool wear and therefore increases the losses. Using high punching speeds requires reliable tool wear prediction or online monitoring of the tool wear to prevent uncontrollable tool wear and subsequent edge deformation. In addition, their 
Fig. 4 Tensile testing in the rolling direction and orthogonal to the rolling direction, and the Johnson-Cook model fit

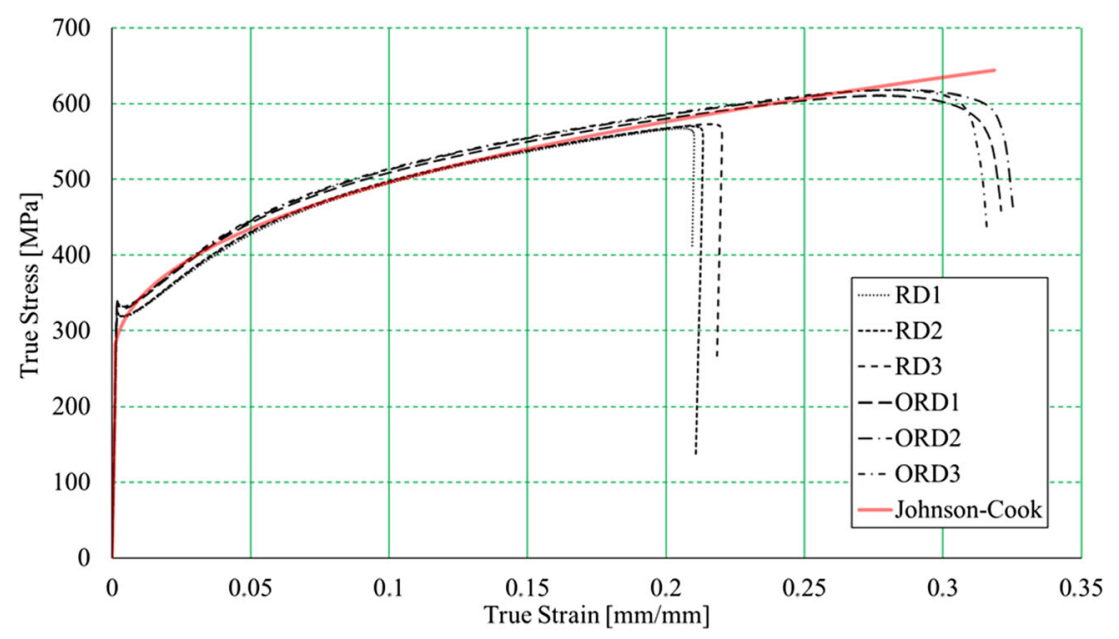

experimental results can be used for verifying the simulation results of punching processes [19]. Wu et al. [20] used optical micrographs and scanning electron microscopy (SEM) to measure plastic strain from the sheared edges in punching. Their results show high strains (peak strain at $3 \mathrm{~mm} / \mathrm{mm}$ ) in the workpiece surface and the strains continue $500 \mu \mathrm{m}$ into the workpiece, or $31 \%$ of the sheet thickness [20]. FEM modeling can be used for simulating the effect of tool wear on burr formation [21]. Senn and Liewald [22] investigated twostage punching to prevent burr formation, using simulations and experiments. Their results show significant improvements in reducing the burr on the cut edge, which would be beneficial also in stator and rotor sheet manufacturing, since the burr causes short circuits in the final product and needs to be removed [22]. Senn and Liewald and Schenek et al. have also investigated the slant angle in punching, which shows a major influence on the process especially in damaging the punching die due to punch bending of the punch [23, 24]. The shape of the cut surface and punching force has been used as the verification data for simulations and no publications are known to the authors where plastic strain is measured on the cut surface and compared against the simulated results.

\section{Materials and methods}

\subsection{M400-50A electrical steel}

Electrical steels are defined in DIN EN 10106 standard to $0.35,0.5,0.65$, and $1.0 \mathrm{~mm}$ thicknesses. This paper investigates M400-50A electrical steel. The M400-50A designation reads as $\mathrm{M}$ for magnetizing steel with maximum iron losses of $4 \mathrm{~W} / \mathrm{kg}$ (400), 50 for a thickness of $0.5 \mathrm{~mm}$, and A for nonoriented grains. M400-50A is alloyed with $\mathrm{Si}$ and $\mathrm{Al}$, and the properties of the material are given in Table 1. Figure 4 shows the tensile testing results of the materials in the rolling direction and orthogonal to the rolling direction.

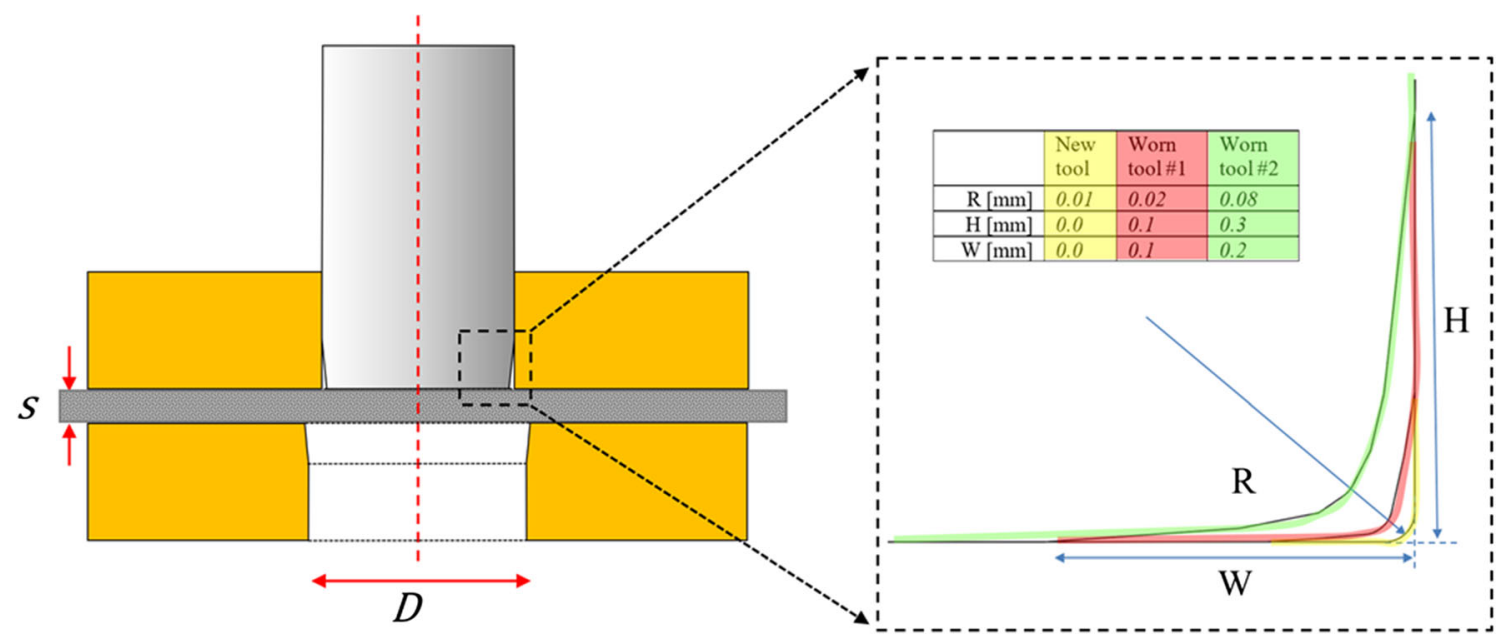

Fig. 5 Simulation setup and tool edge geometries 
Table 2 Johnson-Cook parameters

\begin{tabular}{llllllll}
\hline$A[\mathrm{MPa}]$ & $B[\mathrm{MPa}]$ & $C$ & $n$ & $m$ & $\dot{\varepsilon}_{\text {ref }}\left[\mathrm{s}^{-1}\right]$ & $T_{\text {room }}\left[{ }^{\circ} \mathrm{C}\right]$ & $T_{\text {melt }}\left[{ }^{\circ} \mathrm{C}\right]$ \\
\hline 290.4 & 619.5 & 0.001 & 0.478 & 1 & 0.01 & 20 & 1500 \\
\hline
\end{tabular}

\subsection{Punching}

The punching experiments are done with Müller Weingarten NKA 8-2 groove broaching machine with $80-\mathrm{kN}$ pressing force and punching cycle frequency of 400-1300 1/min. The tool cuts a rotor groove with punchline length $157.5 \mathrm{~mm}$. The tool material is powder-based high-speed steel Vanadis 23.

\subsection{FEM simulations}

The simulations are done with Scientific Forming Technologies Corporation Deform FEM software. Deform uses an updated Lagrangian formulation and a quasi-static implicit solver. Linear quadrature elements with four integration points are used. The model is an axisymmetric 2D simulation of punching a circular hole. The circumference of the punch is matched with the circumference of the real punching tool $(157.5 \mathrm{~mm})$ since the punching line length correlates with the punching force rather than with the punching area. Therefore, the radius of the simulated punch is $25 \mathrm{~mm}$. The simulation setup and tool edge geometries are shown in Fig. 5. The punch is modeled both rigid and elastic to evaluate the effect on modeling accuracy. Three different tool geometries are used, new tool, worn tool \#1, and worn tool \#2. The workpiece is meshed with 13,099 square elements. The element size in the shear zone is $12 \mu \mathrm{m}$. The tool when modeled elastic has 5040 square elements. The elements are linear quadratures with four integration points. Friction in all contacts is Coulomb friction with friction coefficient 0.5 . The simulation time step is $2 \cdot 10^{-5} \mathrm{~s}$. The solver is Sparse solver that is the default in Deform, and time integration is done using the Newton-Raphson iteration scheme.

The flow stress behavior of the material is modeled using the Johnson-Cook material model (Eq. 1) [25] because it is commonly used in the field. The Cockcroft-Latham failure model (Eq. 2) [26] is used for modeling the brittle behavior of the material. The Cockcroft-Latham model was selected due to its simplicity. The parameters for the models are acquired through tensile testing and using digital image correlation with shear testing. Thermal softening behavior is not critical in punching since the cutting temperature does not elevate much over the room temperature. Therefore, the material is set to soften linearly until the melting temperature. The strain hardening coefficient was inversely determined to fit experimental results. The modeling details are explained further in Laakso et al. [3]. The parameters for the Johnson-Cook model are given in Table 2, and the Cockcroft-Latham critical value $C_{\text {crit }}$ was determined to be 400 . The fit of the Johnson-Cook model is shown in Fig. 4. The Cockcroft-Latham model is used together with element deletion, which is known to cause some loss of resolution near the damaged layer caused by the removed elements. The lost resolution is not considered to be
Fig. 6 Cross sections of the punched workpiece mounted in resin (top left) and polished for microhardness testing with Struers DuraScan-70. The microhardness indentation matrix shown in the bottom left

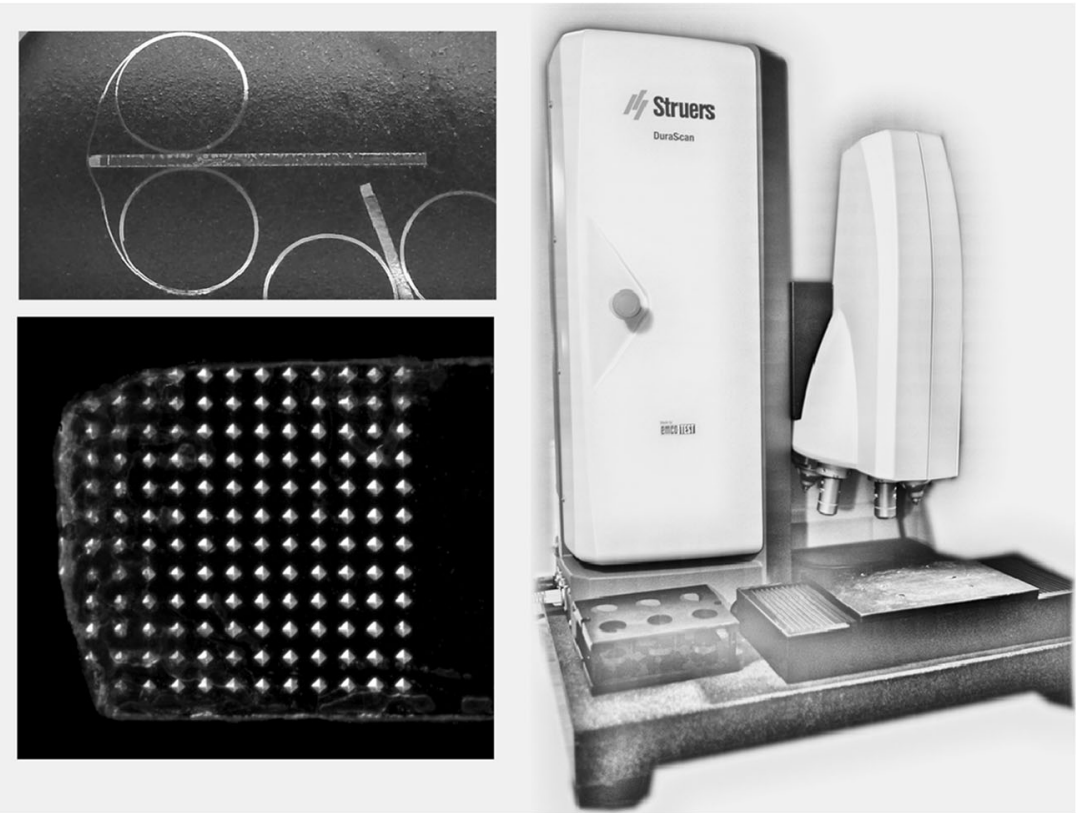


Table 3 Hollomon model parameters and optimal value for $c$

\begin{tabular}{lll}
\hline$K[\mathrm{MPa}]$ & $m$ & $c$ \\
\hline 619.5 & 0.478 & 0.403 \\
\hline
\end{tabular}

a major concern since the element size was small in the shear zone. There is, however, some loss of accuracy as the elements in the shear zone with the highest plastic strains are removed. Therefore, the simulation will predict the maximum strain slightly lower than in reality.

$\sigma=\left(A+B \varepsilon^{n}\right)\left[1+C \ln \left(\frac{\dot{\varepsilon}}{\dot{\varepsilon}_{\text {ref }}}\right)\right]\left[1-\left(\frac{T-T_{\text {room }}}{T_{\text {melt }}-T_{\text {room }}}\right)^{m}\right]$

where $A$ is the yield equivalent, $B$ is the strain hardening multiplier, $n$ is the strain hardening exponent, $m$ is the thermal softening exponent, $\varepsilon$ is the strain, $\dot{\varepsilon}$ is the strain rate, $T$ is temperature, $T_{\text {room }}$ is the reference temperature, and $T_{\text {melt }}$ is the melting temperature.

Fig. 7 The simulated cut surface with rigid a new tool, $\mathbf{b}$ worn tool $\# 1$, and $\mathbf{c}$ worn tool \#2 and elastic $\mathbf{d}$ new tool, $\mathbf{e}$ worn tool \#1, and $\mathbf{f}$ worn tool \#2

a)

$C_{\text {crit }}=\int^{\varepsilon} \sigma^{*} d \varepsilon$

where $\sigma^{*}=$ maximum principal stress and $C_{\text {crit }}=$ critical value.

\subsection{Microhardness testing and prediction of strain}

The microhardness testing is done with Struers hardness tester DuraScan-70 G5. Testing is done with HV0.005 Vickers load with $12 \times 12$ grid in $40-\mu \mathrm{m}$ increments. The total number of measuring points is 144 , including 9 excluded measuring points that were either too close to the edge or the indentation mark was not clear. The samples were cut from the workpiece using wire EDM and then mounted to Struers Polyfast resin, polished, and cleaned for microhardness testing. The mounted samples, the microhardness measuring setup, and the indentation matrix are shown in Fig. 6. Sonmez and Demir tested different analytical expression between Vickers hardness and plastic strain [27]. The model used in the paper, by Tabor and

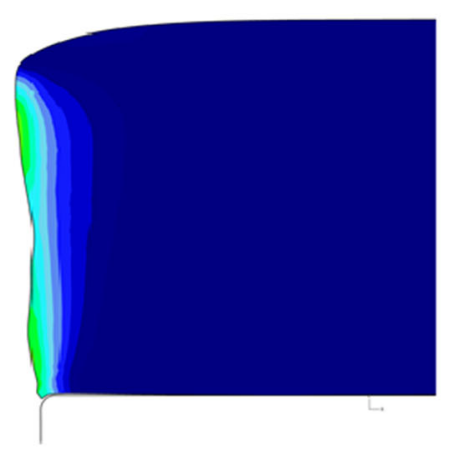

b)

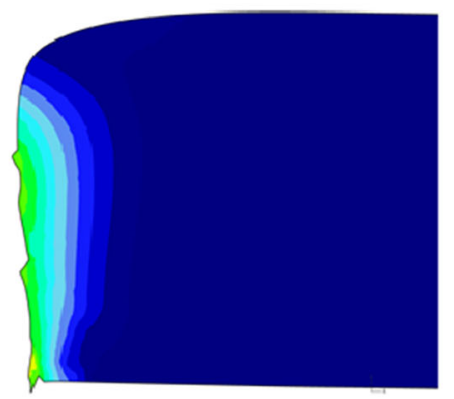

e)
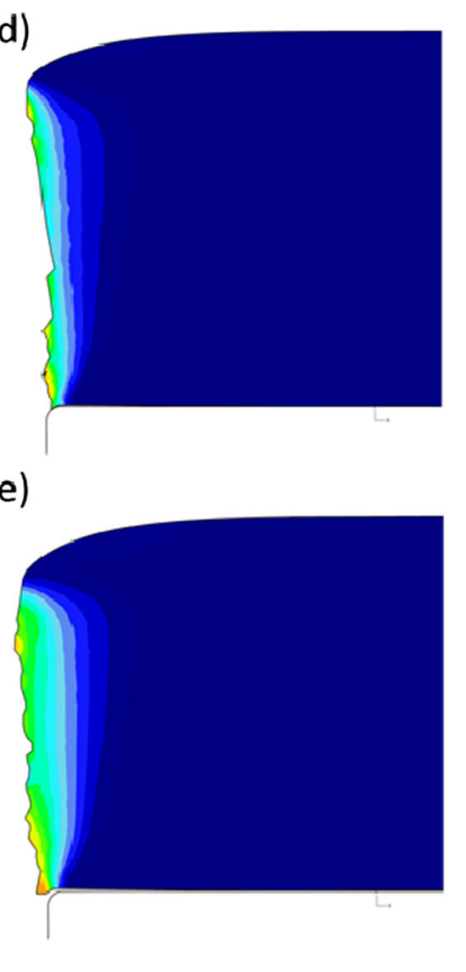

0.3 0.2

0.1 0.0

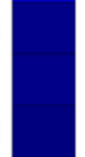

c)

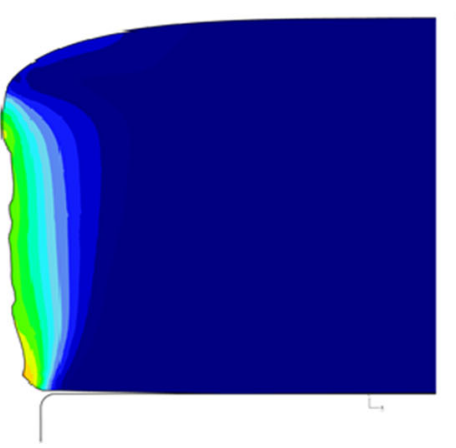

f)

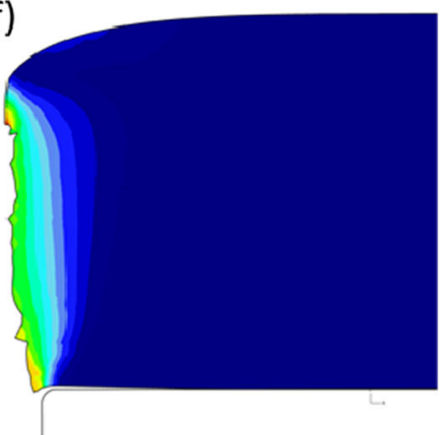




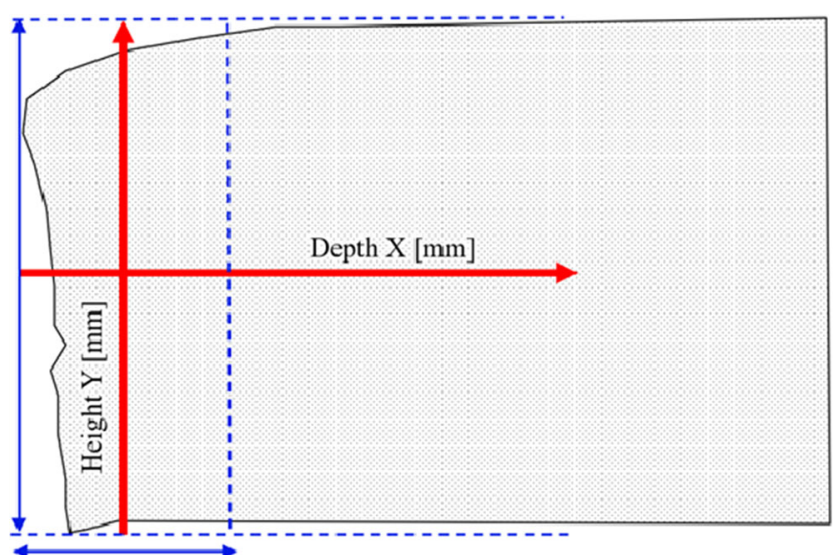

Fig. 8 Plot directions
Taylor [28] (Eq. 3), is in relatively good agreement with the measured harnesses with an average error of $15.7 \%$ based on experiments done by Sonmez and Demir. The model is based on the Hollomon model [29] for strain hardening materials shown in Eq. 4 and the definition of Vickers hardness.

$H_{V}=c K\left(\varepsilon_{0}+\varepsilon_{e}\right)^{m}$

$\sigma=K \varepsilon^{m}$

where $H_{V}$ is the Vickers hardness, $c$ is the experimentally determined multiplier, $\varepsilon_{0}$ is the initial strain, $\varepsilon_{e}$ is the representative strain, $m$ is the strain hardening exponent, and $K$ is the yield strength equivalent. The value for parameter $c$ is determined inversely from the hardness data, using
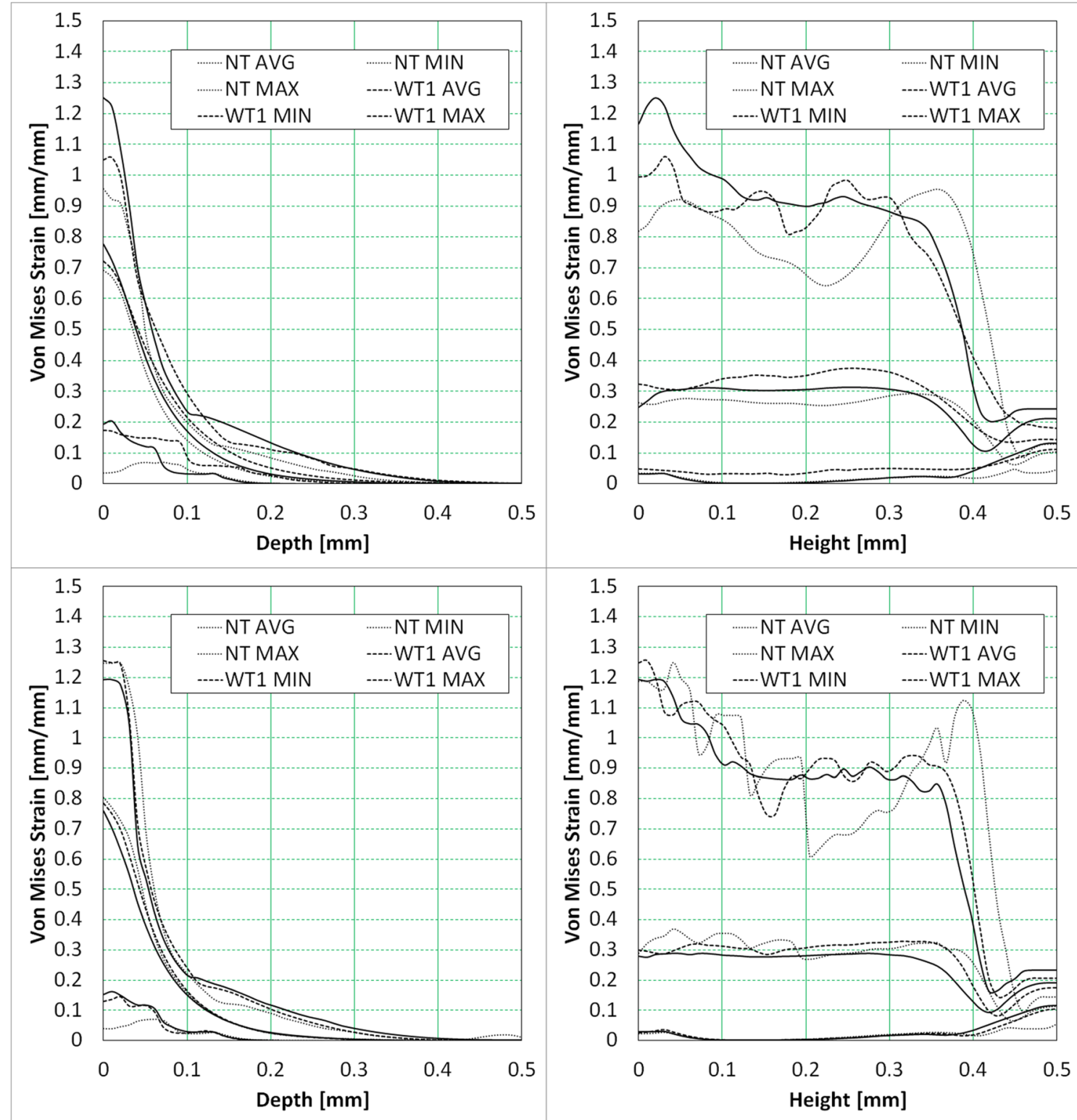

Fig. 9 Strain distributions in depth and height directions, rigid tool up, and elastic tool down 

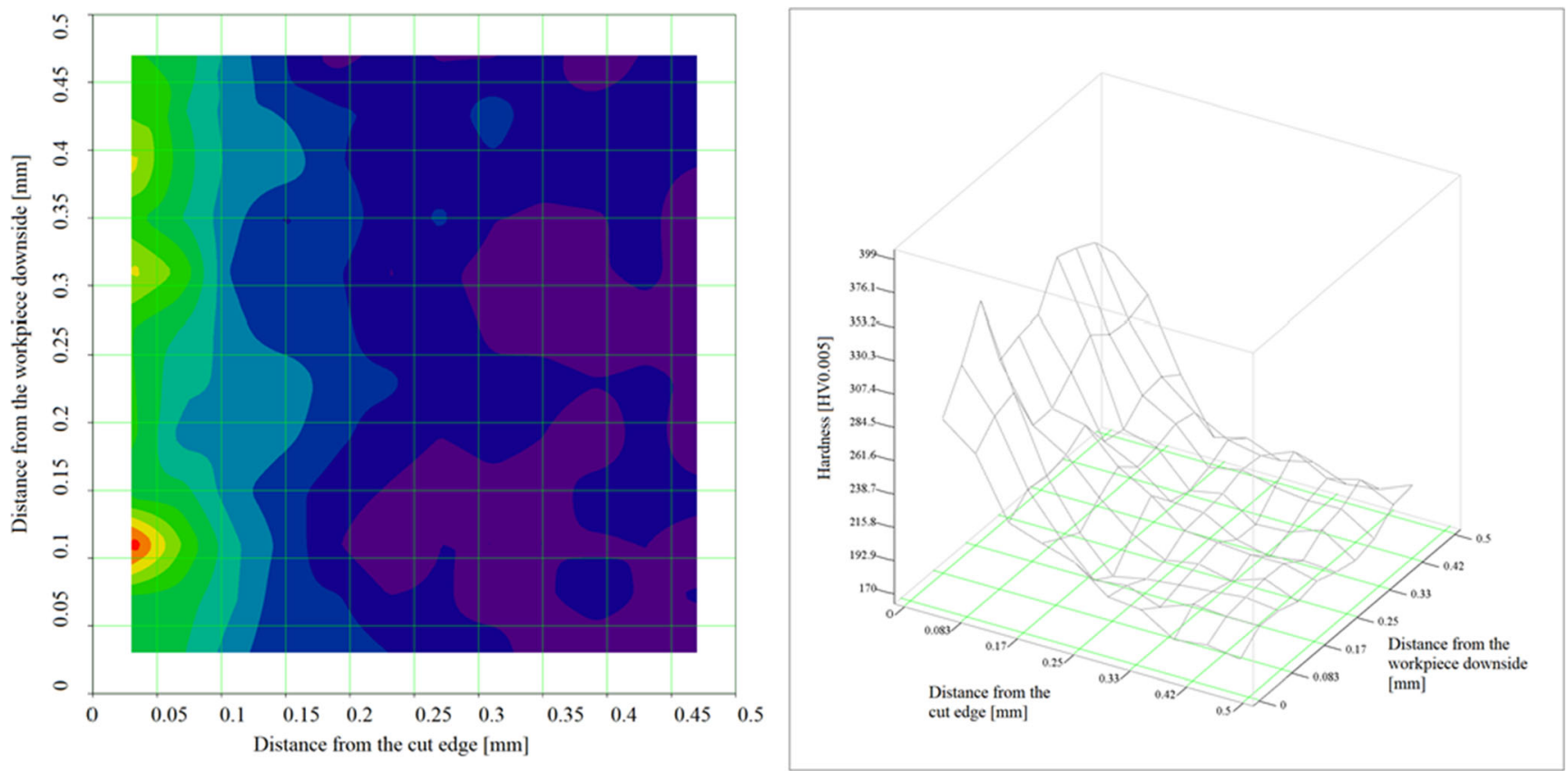

Fig. 10 Microhardness results of the cutting plane cross section, grids in $\mathrm{mm}$ and hardness in Vickers

Levenberg-Marquardt $[30,31]$ method while minimizing the error between measured and predicted $H_{V}$. The values are presented in Table 3 .

\section{Results}

\subsection{Simulation results}

Simulation results show a clear effect of tool wear on cut surface deformations and surface shape. The plastic deformation is increased significantly with the worn tool (Fig. 7). The deformation of the cut surface is evaluated using Von Mises total strain plotted in the directions shown in Fig. 8. The cut surfaces and plastic strains are shown in Fig. 7 and the plotted values in Fig. 9. Whether the tool was modeled rigid or elastic had no major impact on simulation outputs, which can be seen in Figs. 7 and 9.

\subsection{Microhardness testing results}

Microhardness results plotted on the surface cross-section area show that the material deformation is the strongest on the 50 - $\mu \mathrm{m}$-wide deformation zone, after which the deformation is gradually leveling to the stock material values at $300 \mu \mathrm{m}$. Figure 10 shows the measured microhardness. The average standard deviation of the microhardness measurements was $17 \%$. The simulations are in good agreement with the microhardness results, as shown in Fig. 11. Third-order polynomial regression of the hardness was used to plot the values at $H=$ $0.25 \mathrm{~mm}$. The total average error of the simulated hardness compared to measured hardness is $2.9 \%$. Regardless of the excellent fit, the results must be evaluated in a qualitative manner, since there is still unknown uncertainty on converting the microhardness values to plastic strain values, that would require more explicit measurements to determine the accuracy of the strain-hardness conversion.

\section{Discussion}

The simulations show significant plastic deformation on the cutting plane of electric steel sheets for rotor assembly caused by the punching process. It was also shown that increasing tool wear increases the deformations of the cut surface. The

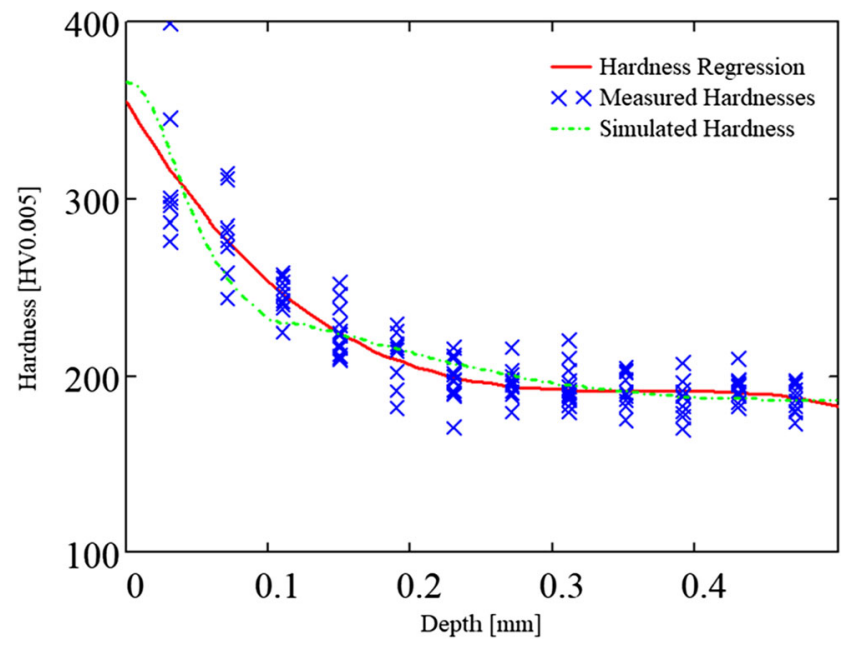

Fig. 11 Comparison of simulated hardness to measured hardness and regression results 
plastic deformation has been shown to increase the iron losses in the cut edges of stator and rotor by $\sim 70 \%$ with a strain increase of $1 \%$ by Aydin et al. [11]. Therefore, controlling the punching process and tool wear is of uttermost importance in manufacturing highest energy efficiency IE5 class electromechanical devices. The simulations are in good comparison with the experimental results, with an average error of $2.9 \%$. There was no major effect whether the tool was modeled rigid or elastic. This is an effect of relatively small loads acting on the tool in punching, compared to for example turning, where tool models have been observed to affect the simulations. The following conclusions can be made:

1. The simulations provide meaningful and accurate results and can be used for optimizing the punching process regarding the cut edge deformations and to determine the critical wear.

2. Based on the results of this investigation and reviewed results from the existing research literature, the punching-induced strains and subsequent losses can be minimized by increasing punching speed and minimizing tool wear by either changing the tool frequently or selecting a more wear-resistant tool material grade.

\section{Future work}

The research will continue regarding tool wear modeling and determination of the critical wear of the punching tool, after which the workpiece surface deformations are higher than the acceptable limits for energy efficiency standards for rotating electrical machinery. Another improvement of the method is required related to the microhardness results, which need to be mapped to verified strain values measured during tensile testing, in order to have a quantitative evaluation of the deformations.

Author contributions Dr. Sampsa Laakso has done the simulations, experiments, analysis of the results, and writing of the paper.

Dr. Ugur Aydin provided expertise on iron losses and loss measurements for the material.

Professor Peter Krajnik was responsible for the quality control and provided the facilities and environment for the work.

Funding Open Access funding provided by Chalmers University of Technology.

Data availability All data is published with the paper.

\section{Compliance with ethical standards}

Conflict of interest The authors declare that there are no conflicts of interest.
Ethical approval This work does not contain any ethical issues or personal information.

Consent to participate No human or animal was involved in this work; thus, no consent was required.

Consent to publish All authors have given their permission for publishing this work.

Code availability The simulation software Deform 12.0 is a commercially licensed product of Scientific Forming Technologies Corporation.

Open Access This article is licensed under a Creative Commons Attribution 4.0 International License, which permits use, sharing, adaptation, distribution and reproduction in any medium or format, as long as you give appropriate credit to the original author(s) and the source, provide a link to the Creative Commons licence, and indicate if changes were made. The images or other third party material in this article are included in the article's Creative Commons licence, unless indicated otherwise in a credit line to the material. If material is not included in the article's Creative Commons licence and your intended use is not permitted by statutory regulation or exceeds the permitted use, you will need to obtain permission directly from the copyright holder. To view a copy of this licence, visit http://creativecommons.org/licenses/by/4.0/.

\section{References}

1. Holopainen TP, Rasilo P, Arkkio A (2016) Identification of magnetic properties for cutting edge of electrical steel sheets. In: 2016 XXII Int. Conf. Electr. Mach. pp 1783-1787. https://doi.org/10. 1109/ICELMACH.2016.7732765

2. Rasilo P, Aydin U, Holopainen TP, Arkkio A (2016) Analysis of iron losses on the cutting edges of induction motor core laminations. In: 2016 XXII Int. Conf. Electr. Mach. pp 1312-1317. https:// doi.org/10.1109/ICELMACH.2016.7732694

3. Laakso SVA, Väänänen A, Bossuyt S, Arkkio A (2018) Dull punch line is not a joke - worn cutting edge causes higher iron losses in electrical steel piercing. Robot Comput Integr Manuf. https://doi. org/10.1016/j.rcim.2018.03.006

4. Bertotti G (1988) General properties of power losses in soft ferromagnetic materials. IEEE Trans Magn 24:621-630

5. Bertotti G (1998) Hysteresis in magnetism: for physicists, materials scientists, and engineers. Elsevier Science https://books.google.se/ books?id=B7xZctzCPfgC. Accessed 24 May 2020

6. Bertotti G (1985) Physical interpretation of eddy current losses in ferromagnetic materials. II. Analysis of experimental results. J Appl Phys 57:2118-2126. https://doi.org/10.1063/1.334405

7. Krings A (2014) Iron losses in electrical machines-influence of material properties, manufacturing processes, and inverter operation. KTH Royal Institute of Technology

8. Serpico C, Visone C, Mayergoyz ID, Basso V, Miano G (2000) Eddy current losses in ferromagnetic laminations. J Appl Phys 87: 6923-6925. https://doi.org/10.1063/1.372887

9. Lukaszczyk M (2014) Improving efficiency in electric motors. World Pumps 2014:34-41. https://doi.org/10.1016/S02621762(14)70080-X

10. Naumoski H, Maucher A, Herr U (2015) Investigation of the influence of global stresses and strains on the magnetic properties of electrical steels with varying alloying content and grain size. In: 2015 5th Int. Electr. Drives Prod. Conf. pp 1-8. https://doi.org/10. 1109/EDPC.2015.7323206 
11. Aydin U, Rasilo P, Martin F, Belahcen A, Kouhia R, Daniel L, Arkkio A (2019) Effect of simultaneous plastic and elastic deformation on magnetic properties of electrical steel sheets. In: 64th Annu. Conf. Magn. Magn. Mater., AIP Publishing, LLC and the IEEE Magnetics Society, Las Vegas. p 442. https://magnetism.org/ storage/app/media/docs/2019MMMFinalAbstractBook20191028. pdf. Accessed 24 May 2020

12. Li JH, Fan WF, Zhang ZM (2010) Study on work hardening performance of pure shearing fine-blanking with negative clearance for ASTM-Gr. D and ASTM-1022 Steel. In: Adv. Mater. Res. pp 145148

13. Schoppa A, Louis H, Pude F, von Rad C (2003) Influence of abrasive waterjet cutting on the magnetic properties of non-oriented electrical steels. J Magn Magn Mater 254-255:370-372. https:// doi.org/10.1016/S0304-8853(02)00882-X

14. Scutaru G (2015) The effect of mechanical and electrical discharge cutting technologies on the magnetic properties of non-oriented silicon iron steels. Rev Roum Des Sci Tech - Ser Électrotechnique Énergétique 60:59-68

15. Siebert R, Schneider J, Beyer E (2014) Laser cutting and mechanical cutting of electrical steels and its effect on the magnetic properties. IEEE Trans Magn 50:1-4. https://doi.org/10.1109/TMAG. 2013.2285256

16. Fyhr P (2018) Electromobility: materials and manufacturing economics. Division of Production and Materials Engineering, Lund University

17. Altan Taylan TAE (2012) Sheet metal forming. ASM International http://app.knovel.com/hotlink/toc/id:kpSMFPA001/sheet-metalforming-processes-2/sheet-metal-forming-processes-2. Accessed 24 May 2020

18. Hambli R, Potiron A (2000) Finite element modeling of sheet-metal blanking operations with experimental verification. J Mater Process Technol 102:257-265. https://doi.org/10.1016/S0924-0136(00) 00496-9

19. Ghadbeigi H, Al-Rubaye A, Robinson FCJ, Hawezy D, Birosca S, Atallah K (2020) Blanking induced damage in thin $3.2 \%$ silicon steel sheets. Prod Eng 14:53-64. https://doi.org/10.1007/s11740019-00931-1

20. Wu X, Bahmanpour H, Schmid K (2012) Characterization of mechanically sheared edges of dual phase steels. J Mater Process
Technol 212:1209-1224. https://doi.org/10.1016/j.jmatprotec. 2012.01.006

21. Hambli R, Soulat D, Chamekh A (2009) Finite element prediction of blanking tool cost caused by wear. Int J Adv Manuf Technol 44: 648-656. https://doi.org/10.1007/s00170-008-1859-9

22. Senn S, Liewald M (2019) A method for producing burr-free shearing surfaces to increase part quality through two-stage counter-cutting. AIP Conf Proc 2113:80014. https://doi.org/10.1063/1. 5112622

23. Senn S, Liewald M (2017) Experimental investigation of piercing of high-strength steels within a critical range of slant angle. J Phys Conf Ser 896:12099. https://doi.org/10.1088/1742-6596/896/1/ 012099

24. Schenek A, Liewald M, Senn S (2019) Identification of process limits for punching with a slant angle. IOP Conf Ser Mater Sci Eng 651:12066. https://doi.org/10.1088/1757-899x/651/1/012066

25. Johnson GR, Cook WH (1983) A constitutive model and data for metals subjected to large strains, high strain rates and high temperatures. In: Proc. 7th Int. Symp. Ballist. pp 541-547

26. Cockcroft MG, Latham DJ (1968) Ductility and the workability of metals. J Inst Met 96:33-39

27. Sonmez FO, Demir A (2007) Analytical relations between hardness and strain for cold formed parts. J Mater Process Technol 186:163173. https://doi.org/10.1016/j.jmatprotec.2006.12.031

28. Tabor D, Taylor GI (1948) A simple theory of static and dynamic hardness. Proc R Soc London Ser A Math Phys Sci 192:247-274. https://doi.org/10.1098/rspa.1948.0008

29. Hollomon JH (1945) Tensile deformation. Am Inst Min Metall Eng Met Technol Technical_1-22

30. Levenberg K (1944) A method for the solution of certain non-linear problems in least squares. Q Appl Math 2:164-168

31. Marquardt D (1963) An algorithm for least-squares estimation of nonlinear parameters. J Soc Ind Appl Math 11:431-441. https://doi. org/10.1137/0111030

Publisher's note Springer Nature remains neutral with regard to jurisdictional claims in published maps and institutional affiliations. 